\title{
Correction to: Becoming Citizens in a Changing World
}

\section{Correction to:}

W. Schulz et al., Becoming Citizens in a Changing World, https://doi.org/10.1007/978-3-319-73963-2

On the copyright page (page iv), below the IEA logo and text, an "All rights reserved..." statement was inadvertently added. This statement has now been deleted, as this is an open access book.

The updated original online version for this book can be found at https://doi.org/10.1007/978-3-319-73963-2 